INNOVATIONS IN PRIMARY CARE

\title{
Engaging Complex Patients With Drop-In Group Medical Appointments
}

\author{
Bryan Hodge, DO, Steven Crane, MD \\ Ann Fam Med 2017;15:279. https://doi.org/10.1370/afm.2065.
}

\section{THE INNOVATION}

Traditional primary care is not designed to engage and support patients with complex social, behavioral health, and medical needs. Our Bridges to Health program offers drop-in group medical appointments (DIGMAs) that include a physician, a nurse care manager, a behavioral health counselor, peer support, a consulting occupational therapist, and a clinical pharmacist to provide a safe, accessible environment for such patients. Other services include care management; medication assistance; and transportation, nutrition, and social support. Over 6 years we have enrolled more than 500 patients, reduced their hospital utilization about $50 \%$, and improved functional scores in over $2 / 3$ of them. Once stabilized, most are able to transition to traditional primary care.

\section{WHO AND WHERE}

Our program is a collaboration between a free clinic, a family medicine residency program, a federally qualified health center, and a Medicaid managed care program; it targets low-income individuals in Henderson and Polk Counties, NC, who have no insurance or Medicaid and who demonstrate multiple needs and barriers to traditional primary care.

\section{HOW}

Our original pilot included about 40 of the 255 low-income, uninsured patients who had had at least 6 visits to our county hospital in the previous year-225 patients who represented $0.2 \%$ of the county population but received $50 \%$ of the uncompensated hospital care. Nearly all suffered from serious trauma or PTSD, at least 1 chronic medical problem, and untreated mood disorders. Many suffered from substance abuse and homelessness. Our model focuses on eliminating

Conflicts of interest: authors report none.

\section{CORRESPONDING AUTHOR}

Bryan Hodge, DO

MAHEC-Hendersonville Rural Family Medicine Residency Program

Hendersonville, NC 28791

bhodge@brchs.com all barriers to care and creating a safe, predictable source of care where a team will accept patients without judgment, help them set goals, and support them in addressing the issues they themselves identify as most pressing. Patients can attend as many DIGMAs as they choose without cost and receive meal or transportation vouchers if need be. Between DIGMAs, patients can call the nurse manager, and the nurse has direct access to the physician for acute problems. The typical 1-hour DIGMA involves 4 to 9 patients and begins with a short mindfulness exercise. Patients then take turns updating the group on their progress and issues and receiving feedback from the group and the care team. A 30-minute period is reserved for patients needing individual care. Most patients utilize the DIGMA at least weekly for the first month or 2 and gradually reduce the frequency of visits as their conditions improve. Patients usually progress toward regular primary care in 9 to 12 months. We now enroll about 120 patients a year into any of 3 weekly DIGMAs. The grant-funded program is now in its sixth year at a cost of about $\$ 100$ per enrolled patient per month.

\section{LEARNING}

We have learned several lessons from this project: Patients with complex needs will engage in their care only when they feel valued and listened to. Until we understand what happened to our patients, we don't really understand how to support them. Most complex patients have amazing resilience and have persevered through extremely difficult circumstances. Community matters; patients feel a stronger sense of support from their peers and the team. This fosters accountability, hope, and a desire to help others, and by helping others, they help themselves. This improvement takes time and patience, and it is rarely linear. Additionally, relationships matter at all levels. Providing team-based care with the entire team present during a DIGMA makes full use of the skills and experience of each team member. Patients can teach us what matters most in their lives and can reconnect us to the reason most of us went into healthcare in the first place.

Key words: multimorbidity; trauma and stressor related disorders; patient care team; vulnerable populations; group medical appointments

Author affiliations and information about funding support and prior presentations are available at http://www.AnnFamMed.orgl content/15/3/279/suppl/DC1. 